\title{
EL DERECHO DE TODAS LAS MUJERES A PERCIBIR LA ASIGNACIÓN UNIVER- SAL POR HIJO
}

\section{THE RIGHT OF ALL WOMEN TO RECEIVE THE UNIVERSAL CHILD ALLOWANCE}

\section{María Florencia Blanco Pighi ${ }^{1}$}

DOI: https://doi.org/10.37767/2591-3476(2021)14

\section{Comentario a}

Recurso de hecho deducido por la Administración Nacional de la Seguridad Social en la causa Internas de la Unidad $n^{\circ} 31$ SPF y otros s/habeas corpus

Corte Suprema de Justicia de la Nación

\author{
Disponible en \\ https://bit.ly/38hUAdl
}

\section{RESUMEN:}

La Corte Suprema de Justicia de la Nación, al resolver el recurso extraordinario interpuesto, estableció que las asignaciones familiares son un derecho de los progenitores, debiendo ser pagadas por el Estado, aun cuando los niños en cuestión se encuentren viviendo en un establecimiento penitenciario, en virtud de que sus madres han optado por esa modalidad. El más alto tribunal argentino estableció que interpretar lo contrario, implicaría un agravamiento ilegítimo de las condiciones originarias de detención. Estos beneficios de la seguridad social, implican garantizar el acceso de los niños y niñas a un adecuado nivel alimentario, de salud, vestimenta, entre otros derechos humanos inalienables, no siendo admisible su privación por el solo hecho de que la progenitora y el niño se alojen dentro del sistema penitenciario argentino. En este contexto, cobra relevancia el habeas corpus como herramienta central para la protección de las personas detenidas y la normativa de derechos humanos que goza de raigambre constitucional en nuestro país.

\section{ABSTRACT}

The Argentine Supreme Court of Justice, when deciding the extraordinary appeal filed, established that family allowances are a right of the parents, and must be paid by the State, 
even when the children in question are living in a penitentiary, due to their mothers have opted for this modality. The highest Argentine court established that interpreting the opposite would imply an illegitimate aggravation of the original conditions of detention. These social security benefits imply guaranteeing the access of kids to an adequate level of food, health, clothing, among other inalienable human rights, their deprivation is not admissible based on the fact that the parent and the child are housed in the prison system. In this context, habeas corpus becomes relevant as a central tool for the protection of detained persons and the human rights regulations that enjoy constitutional roots in our country.

PALABRAS CLAVE: Habeas corpus; asignaciones familiares; igualdad; derechos humanos; sistema penitenciario.

KEY WORDS: Habeas corpus; family's assignations; equality; human's rights; prison system.

\section{Introducción}

A continuación, se procederá a analizar de manera concreta el fallo: “Recurso de hecho deducido por la Administración Nacional de la Seguridad Social en la causa Internas de la Unidad n 31 SPF y otros s/habeas corpus" de fecha 11 de febrero de 2020.

La causa se inicia con la interposición del habeas corpus efectuada por la Procuración Penitenciaria de la Nación, en representación de mujeres embarazadas privadas de la libertad, como así también de aquellas que optaron por permanecer encarceladas con sus hijos menores de cuatro años bajo su cuidado, a los fines de que se les reconociera el derecho a percibir las asignaciones familiares: la asignación por hijo, la asignación universal por hijo y la asignación universal por embarazo, según el caso.

La Cámara Federal de Apelaciones de La Plata, Sala III, rechazó el pedido de habeas corpus, por lo que se interpuso recurso de casación, el que fue resuelto de manera favorable por la Cámara Federal de Casación Penal, Sala IV. Ante esta resolución, la Administración Nacional de la Seguridad Social (ANSES) interpuso recurso extraordinario cuya denegación dio origen a un recurso de queja, por el que interviene la Corte Suprema de Justicia de la Nación.

Así las cosas, el más alto tribunal argentino confirmó la decisión de la cámara de casación, al entender que los derechos de los niños y niñas alojados en el servicio penitenciario, como así también sus madres, requieren de una protección integral para garantizar el ejercicio y disfrute pleno, efectivo y permanente reconocido, no solo por nuestro ordenamiento interno sino también por el derecho internacional.

En este marco, el presente artículo pretende analizar los derechos en pugna y su protección constitucional e internacional, a los fines de dilucidar si la decisión de la Corte Suprema de Justicia de la Nación es acorde a la normativa vigente en la materia.

\section{Reseña del caso. Las diferentes posturas}

La ANSES había establecido no otorgar las asignaciones familiares por hijo, asignación 
universal por hijo ni asignación universal por embarazo, a las mujeres que se encontraban cumpliendo condena dentro del sistema penitenciario, por entender que las necesidades a las que están destinadas dichos fondos ya se encontraban cubiertas por el Estado, ya que el propio sistema penitenciario asegura la asistencia y el cuidado de los niños y niñas allí alojados.

La Procuración Penitenciaria de la Nación y la Defensoría General de la Nación plantearon un habeas corpus al interpretar que se configuraba un agravamiento ilegítimo de las condiciones en las que se cumple condena y que el rechazo de cobertura de estos beneficios de la seguridad social no tiene su origen en la ley, ya que la normativa vigente no excluye a las mujeres presidiarias de los mismos, no existiendo alusión alguna a este supuesto dentro de nuestro marco legal.

\section{Algunas aclaraciones conceptuales}

Resulta fundamental distinguir los tres institutos a los que hace alusión el fallo en cuestión, ya que, si bien se tratan de beneficios de la seguridad social, cubren situaciones diferentes, a pesar de estar todas contempladas en la misma norma, la que, a la fecha, ha sufrido varias reformas.

Cuando hablamos de asignaciones familiares, nos referimos a las creadas por la Ley $\mathrm{N}^{\circ} 24.714$, es decir, a ciertos montos que se abonan de manera periódica o por única vez a aquel que tiene la obligación y la responsabilidad de asumir cargas vinculadas a la familia, las que son soportadas, en general, por la parte patronal. Para la Asociación Internacional de la Seguridad Social se trata de:

"toda asignación en especie o en dinero cuyo objeto es permitir la construcción o el desarrollo de las familias, ya por aportación regular y constante de una contribución al sustento de las personas a cargo del cabeza de familia, ya por medio de una ayuda especial en determinados momentos de la vida de la familia"2.

Las asignaciones familiares se caracterizan por ser uniformes, unitarias, obligatorias y universales. Se basan en el principio de solidaridad, ínsito en todo instituto de seguridad social ${ }^{3}$.

Dentro de las asignaciones previstas por la normativa citada, se enumeran las siguientes: asignación por hijo, asignación por hijo con discapacidad, asignación prenatal, asignación por ayuda escolar anual para la educación inicial, general básica y polimodal, asignación por maternidad, asignación por nacimiento, asignación por adopción, asignación por matrimonio, asignación Universal por Hijo para Protección Social, asignación por Embarazo para Protección Social y la asignación por Cuidado de Salud Integral.

En nuestro país, los únicos límites establecidos a la percepción de las asignaciones familiares, legalmente dispuestos, se relacionan con el monto de la remuneración del trabajador (cuando el progenitor o la progenitora que las percibe se encuentra vinculado laboralmente de manera registrada), existiendo topes en ese aspecto, y la exclusión expresa de los trabajadores del servicio doméstico.

\footnotetext{
2 "Función social de los regímenes de asignaciones familiares" en Documentos A.I.S.S., Palpa 1977, p. 6. Disponible en: https://wwl.issa.int/es/recognition/ documents fecha de consulta 30/06/2021

3 Ruprecht, Alfredo J. Asignaciones Familiares. Buenos Aires. 1998. Ed. Zavalía. P. 14 y 19.
} 
Así las cosas, podemos distinguir, en torno al caso que nos ocupa, la asignación por hijo, para el caso de tener un progenitor o progenitora que esté en relación de dependencia, quedando bajo la órbita del sistema contributivo previsto por la Ley 24.714. Por otro lado, dentro del subsistema no contributivo de la norma, la Administración Nacional de la Seguridad Social (ANSES) se encarga del pago de la Asignación Universal por Hijo (A.U.H.) y la Asignación Universal por Embarazo (A.U.E.).

Ambos institutos fueron incorporados a la norma con posterioridad a su sanción, y responden a un fuerte convencimiento de la necesidad de proteger el embarazo y las infancias, pudiendo cubrir ciertas necesidades a partir del pago de esas asignaciones. La A.U.H. fue incorporado por art. $4^{\circ}$ del Decreto $N^{\circ} 1602 / 2009$, y la A.U.E. fue incorporado por art. $2^{\circ}$ del Decreto $N^{\circ} 446 / 2011$.

Por otra parte, es fundamental mencionar que el acceso a los beneficios de la seguridad social, constituye un derecho humano inalienable de toda persona, y que debe ser protegido por el Estado.

\section{La normativa en juego}

\section{Las leyes nacionales}

Como ya mencionáramos, las asignaciones familiares, en sentido amplio, se encuentran contempladas en la Ley № 24.714, pero, asimismo las leyes № 24.463 y № 26.417 establecen la movilidad de las prestaciones de la seguridad social. Es decir que, todo lo atinente a este tipo de beneficios se encuentran regulados en dichas normas y sus modificatorias. Además, la A.U.H se encuentra reglamentada mediante Resolución 393/2009 de la ANSES.

A su vez, Argentina ha sancionado la Ley № 26.485, llamada de Protección Integral para Prevenir, Sancionar y Erradicar la Violencia contra las Mujeres en los Ámbitos en que Desarrollen sus Relaciones Interpersonales, la que ha sido considerada en el fallo en cuestión, por interpretarse que la negativa al pago de estas asignaciones a las mujeres alojadas dentro del servicio penitenciario constituye una forma de violencia institucional (art. 6).

Por otro lado, la Ley № 24.660, mediante el art. 195, les concede a las mujeres que han sido condenadas con penas privativas de la libertad, a transitar su embarazo y vivir con sus hijos e hijas hasta que cumplan los cuatro años de edad, dentro del sistema penitenciario. Es decir, que la situación de convivencia con los niños dentro de la unidad carcelaria donde están alojadas, también responde a una posibilidad establecida por la ley.

Otra norma importante, a los fines de dilucidar los alcances de la acción impetrada, es la ley $N^{\circ} 23.098$ que rige el procedimiento de la garantía constitucional del habeas corpus, para los casos en los que se produjese una agravación ilegítima de la forma y condiciones en que se cumple la privación de la libertad (art. 3 inc. 2).

Finalmente, nuestro país dictó la Ley № 26.061 de Protección integral de los derechos de las niñas, niños y adolescentes, que establece la importancia de tener en miras el interés superior del niño (art. 3) y que se deben tomar en cuenta políticas públicas que promuevan el fortalecimiento del rol de la familia (art. 4). En dicha norma, se garantiza su derecho a la vida, salud y educación, todas necesidades contempladas por las asignaciones familiares, en términos de su implementación para que sean satisfechas. 


\section{Normas constitucionales}

La Constitución Nacional prevé en el art 14 bis que el Estado otorgará los beneficios de la seguridad social, que tendrá carácter de integral e irrenunciable, manifestando que se asegurará la protección integral de la familia. Es relevante destacar que la normativa constitucional no establece ninguna distinción ni en el tipo de familia ni en la situación de libertad de sus integrantes, a los fines de la efectividad de este resguardo.

En concordancia con esta protección, el art. 75 inc. 23 pone en cabeza del Congreso de la Nación la obligación de legislar medidas de acción positiva que garanticen la igualdad real de oportunidades y de trato, y el pleno goce y ejercicio de los derechos reconocidos por esta Constitución y por los tratados internacionales vigentes sobre derechos humanos, en particular respecto de los niños, las mujeres, los ancianos y las personas con discapacidad. A su vez, se establece el deber de dictar un régimen de seguridad social especial e integral en protección del niño en situación de desamparo, desde el embarazo hasta la finalización del período de enseñanza elemental, y de la madre durante el embarazo y el tiempo de lactancia. Es decir que, expresamente, la manda constitucional establece la necesidad de proteger a mujeres, niños y niñas, en un marco de igualdad real de oportunidades.

De igual manera, el art. 18 de nuestra Carta Magna establece que:

"Las cárceles de la Nación serán sanas y limpias, para seguridad y no para castigo de los reos detenidos en ellas, y toda medida que a pretexto de precaución conduzca a mortificarlos más allá de lo que aquélla exija, hará responsable al juez que la autorice".

En consonancia con esta norma, el art. 43, en su última parte, establece la posibilidad de interponer acción de habeas corpus, para garantizar el cumplimiento y la protección de los derechos de las personas encarceladas o detenidas.

El art. 28 de nuestra Constitución Nacional, expresamente regula que las leyes que reglamenten el ejercicio de los derechos y garantías contemplados por nuestra constitución no pueden alterar su espíritu. Con lo cual, ninguna norma posterior que dictara el Poder Legislativo, o incluso ninguna resolución de los organismos gubernamentales, ni un decreto del Poder Ejecutivo, podrían violentar la intención expresa del constituyente que se evidencia en el articulado citado.

\section{Tratados internacionales de derechos humanos}

Nuestro país ha firmado una serie de tratados internacionales cuyo contenido es protectorio de derechos humanos, incluso algunos de ellos gozan de jerarquía constitucional a partir de la reforma del año 1994 (art. 75 inc. 22 C.N.).

Entre estos tratados, algunos se relacionan directamente con la temática en cuestión, pudiendo mencionar, sin pretender ser exhaustivos: el Pacto Internacional de Derechos Económicos, Sociales y Culturales (que reconoce el derecho al acceso a la seguridad social, art. 9), la Convención Americana sobre Derechos Humanos (que establece el principio de no trascendencia de la pena, art. 5), la Convención sobre la Eliminación de todas las Formas de Discriminación contra la Mujer (que le asegura el acceso a la seguridad social en los arts. 11 y 13) y la Convención sobre los Derechos del Niño (que establece que siempre se tendrá en cuenta el interés superior del niño, art. 3, como así también la protección integral y un desarrollo de vida adecuado, art. 27). 
En el marco de la Declaración Universal de los Derechos Humanos, se establece en el art. 25 "que toda persona tiene derecho a un nivel de vida adecuado que le asegure, así como a su familia, la salud y en especial la alimentación, el vestido, la vivienda, la asistencia médica y los servicios sociales necesarios". En consonancia con el art. 12 del Pacto Internacional de Derechos Económicos, Sociales y Culturales, mencionado con anterioridad.

Queda claro entonces que el acceso a estos beneficios de la seguridad social incide de manera directa en el acceso y el goce pleno que tiene toda persona de su derecho a la salud. Así lo ha entendido también el Comité de las Naciones Unidas de Derechos Económicos, Sociales y Culturales ${ }^{4}$, que plantea que el derecho a la salud está estrechamente vinculado con el ejercicio de otros derechos humanos y depende de esos derechos, en particular el derecho a la alimentación, a la vivienda, al trabajo, a la educación, a la dignidad humana, a la vida, a la no discriminación, a la igualdad, a no ser sometido a torturas, a la vida privada, al acceso a la información y a la libertad de asociación, reunión y circulación.

En este sentido, los derechos humanos se caracterizan por estar interrelacionados, ser interdependientes e indivisibles ${ }^{5}$, razón por la cual, la falta de acceso o de protección de uno de ellos, ineludiblemente implicará la privación o vulneración de otros.

\section{Los derechos de los niños y niñas}

Si bien el eje central del fallo es la concesión o no de las asignaciones familiares a las mujeres madres insertas en el sistema penitenciario, no debemos perder de vista que todas estas prestaciones estatales tienen en miras la protección y satisfacción de necesidades de niños y niñas.

En este aspecto, deviene central tomar en cuenta su interés superior, que ha sido considerado el corazón de la Convención sobre los derechos del niño. Así las cosas, este interés es el que debe orientar y condicionar las decisiones de los tribunales de todas las instancias ${ }^{6}$.

La mencionada Convención también protege los derechos económicos y sociales de los niños, niñas y adolescentes, si bien se ha puesto de resalto que su exigibilidad ha tenido baja intensidad y en muchos países, en especial de América Latina, los Estados vulneran estos derechos económicos y sociales por omisión. Asimismo, el tratamiento académico de la temática, suele reducir el análisis a los derechos civiles de los niños, niñas y adolescentes y a todo lo relativo al régimen penal juvenil, existiendo un escaso tratamiento de los demás derechos que son contemplados por la Convención?.

Dentro de los derechos sociales a los que se hace referencia este tratado internacional, se debe citar el acceso a la vivienda, el derecho a la alimentación, a la educación, entre otros. Muchos de estos derechos, son los que se intenta proteger mediante el acceso a las asignaciones familiares.

\footnotetext{
4 Oficina del Alto comisionado de las Naciones Unidas para los Derechos Humanos - OACNUDH (1991): “Observación general N 14: El derecho al disfrute del más alto nivel posible de salud (Art. 12 del Pacto)”. Disponible en: https://tbinternet.ohchr.org/_layouts/15/treatybodyexternal/Download.aspx?symbolno=E $\% 2$ fC. $12 \% 2$ f2000\%2f 4 \&Lang=en fecha de consulta: 02/06/2021.

5 De Cicco, Andrés Oscar, Riesgo habitacional de personas vulnerables y su impacto en el derecho a la salud: la conducta omisiva del estado provincial en Revista Derecho y Salud. Sala de Derecho a la salud. EUBP. Año 3. No 3. Noviembre de 2019. P. 192.ISSN (Versión impresa): 2591-3468. ISSN (Versión online): 2591-3476. 6 CSJN. Fallos: 341:1733

7 MORENO, Gustavo Daniel. La gran ausencia en el ejercicio de la convención. La exigibilidad de los derechos económicos, sociales y culturales en: A 30 años de la Convención sobre los derechos del niño. Avances, críticas y desafíos. Dir. Herrera, M. Gil Dominguez, A. Giosa, L. Buenos Aires, Ediar, 2019. P. 140-141.
} 
En este sentido, resulta fundamental que, los operadores del derecho, pero sobre todo el Estado, sean garantes del cumplimiento de los derechos que se plasman en los instrumentos internacionales, ya que la exigibilidad de los mismos pareciera ser la gran ausente del ejercicio convencional ${ }^{8}$.

Por supuesto que no escapa a nuestro entendimiento que existe una vinculación muy fuerte entre la pobreza que sufren los niños, niñas y adolescentes y el acceso a la justicia, relación que ha sido tratada por el documento internacional conocido como las Cien Reglas de Brasilia'9, ya que, la pobreza constituye una causa de exclusión social y es el Estado quien debe garantizar las medidas de protección necesaria para los casos de niños y niñas en situación de riesgo ${ }^{10}$.

Consideramos que se encuentran dadas todas las condiciones para que los derechos económicos y sociales de los niños, niñas y adolescentes sean exigibles, ya que así ha sido establecido por el Comité de los Derechos del Niño de las Naciones Unidas ${ }^{11}$.

En esta línea de pensamiento, se ha dicho que, en nuestro país, existen cuatro mecanismos fundamentales de injusticia y exclusión, a saber: el racismo, el clasismo, la desigualdad de género y la inequidad territorial ${ }^{12}$. En el caso que nos ocupa estamos ante una población que es excluida en virtud de la mayoría de estos factores.

Podemos decir que, la acción interpuesta por la Procuración Penitenciaria de la Nación, si bien no lo hace de manera expresa, exige al Estado Argentino que se garanticen los derechos de esos niños y niñas, a través de la asignación que se les otorga a sus madres, encargadas de su cuidado.

\section{La interpretación armónica de las normas y la supremacía constitucional}

De un análisis pormenorizado de toda la normativa citada, podemos establecer que las asignaciones familiares son un derecho que tienen los progenitores que trabajan en relación de dependencia (sistema contributivo) o los progenitores que tienen a sus hijos a su cargo a pesar de no encontrarse trabajando o no hacerlo de manera registrada (sistema no contributivo). El acceso a estas asignaciones permite que los niños, niñas y adolescentes que son los beneficiarios de las mismas, puedan acceder a derechos de tipo económico y social, los que son garantizados por normas nacionales y supra nacionales.

A su vez, la normativa interna de nuestro país, que regula las cuestiones relativas a las asignaciones familiares no establece ningún tipo de distinción en torno al lugar donde se encuentre viviendo el progenitor o progenitora que percibe la asignación que beneficia al niño o niña, por lo cual la situación de encontrarse cumpliendo algún tipo de condena no debería ser obstáculo para su percepción. Por otro lado, tampoco distingue en cuanto a la forma del trabajo en relación de dependencia, por lo cual, si la progenitora presta

\footnotetext{
8 Moreno, Op. Cit.... p. 142.

9 Cien Reglas de Brasilia sobre Acceso a la Justicia de las Personas en condiciones de vulnerabilidad, adoptadas en la Asamblea Plenaria de la XIV Edición de la Cumbre Judicial Iberoamericana, 2008, a las que ha adherido la CSJN mediante Acordada N ${ }^{\circ}$ 5/2009. Disponible en: https://www.acnur.org/fileadmin/ Documentos/BDL/2009/7037.pdf Fecha de consulta: 28/05/2021.

10 CIADH, "Villagrán Morales y otros- caso de los niños de la calle" Sentencia del 19/11/1999.

11 O.N.U., Observación General Nº 5, 27/11/2003. Disponible en: https://www.unicef.org/UNICEF-ObservacionesGeneralesDelComiteDeLosDerechosDelNi no-WEB.pdf Fecha de consulta: 28/05/2021

12 Grimson, Alejandro. La formación ciudadana en sociedades desiguales y heterogéneas en La educación argentina: la urgencia del largo plazo. Tedesco, Juan Carlos, compilador. Buenos Aires, Siglo veintiuno editores, 2015. P. 105
} 
tareas remuneradas dentro del Servicio Penitenciario, es su derecho legal, garantizado por el art. 14 bis C.N., percibir la asignación familiar por sus hijos.

En este sentido, podemos decir que las leyes nacionales de nuestro país, como así también el marco legal de los tratados internacionales de derechos humanos que Argentina ha suscripto y ratificado, al igual que nuestra Constitución Nacional, son armónicos en este punto y aseguran el acceso de todas las personas a estos beneficios de la seguridad social.

Se garantiza, entonces, por medio de la normativa invocada, la protección de los niños, niñas y adolescentes, como así también de las mujeres y de las personas que se encuentran privadas de la libertad.

Además, el acceso a los beneficios de la seguridad social se encuentra íntimamente ligado con el derecho a la salud de las personas en contextos de encierro y de los hijos e hijas que se encuentran a su cargo en el sistema penitenciario, siendo obligación del Estado Argentino garantizar condiciones carcelarias dignas para esa población, debiendo asegurar y promover su bienestar psicofísico ${ }^{13}$.

\section{A modo de conclusión}

A la luz de todo lo analizado, podemos concluir que la solución establecida por nuestra Corte Suprema de Justicia de la Nación es ajustada a derecho y a todo sentido de justicia, cumpliendo así con la manda supra nacional de garantizar la protección y el efectivo cumplimiento de los derechos humanos que regulan las convenciones en las la República Argentina es parte.

Interpretar de otra manera lo establecido por el más alto tribunal argentino implicaría discriminar a las mujeres que se encuentran privadas de su libertad y, lo que es más grave aún, desproteger a sus hijos e hijas, los que no han podido decidir en absoluto sobre la situación en la que se encuentran.

Privar a las mujeres que están presas de las asignaciones que les corresponden por su trabajo o de las que deberían percibir en beneficio de los hijos e hijas a su cargo (nacidos o por nacer), por el hecho de que el Estado ya cubre sus necesidades a través del sistema penitenciario, implica, sin lugar a dudas, agravar las condiciones de su detención y colocarlas en una situación de mayor vulnerabilidad, lo cual es, inaceptable.

Ha quedado probado en la causa en comentario que, muchas de las necesidades de las mujeres que se encuentran en contextos de encierro deben ser cubiertas por ellas mismas, por medio de compras que realizan dentro del propio establecimiento carcelario y que lo mismo ocurre con algunos bienes que deben comprar para sus hijos e hijas. Que, en este aspecto, deviene obvio que, impedirles percibir las asignaciones mencionadas, implicaría privarlas de cubrir esas necesidades propias y de sus hijos e hijas. Este argumento de ANSES no puede ser de recibo, ya que coloca en una situación de mayor indefensión y discrimina a estas mujeres insertas en el sistema penitenciario argentino.

Entendemos que, cuando una mujer realiza la opción que la ley le permite de tener un

13 Copello, Nadia Virginia. Derecho a la salud intramuros en: Revista Derecho y Salud. EUBP. Año 4. Nº 5. Diciembre, 2020. P. 282. ISSN (versión impresa): 2591-3468. ISSN (versión online): 2591-3476. 
hijo o hija a su cargo dentro del sistema penitenciario, debe poder gozar del acceso a la A.U.H. o asignación familiar, según corresponda. Privarla de este beneficio es contrario a derecho e implica una discriminación injustificada que podría generar la responsabilidad de nuestro país ante organismos internacionales, por constituir un flagrante incumplimiento de las normas de derechos humanos que hemos ratificado y cuya operatividad debemos garantizar.

Así las cosas, el Estado argentino está obligado no solo a dar cumplimiento a lo establecido en los tratados de derechos humanos que ha ratificado, sino que los poderes que lo integran, deben asegurar que las normas contenidas en los mismos gocen de plena operatividad, garantizando el goce y ejercicio de los derechos protegidos por la normativa invocada. Todo ello, acaece en el fallo analizado, garantizándole a las mujeres privadas de la libertad, el acceso pleno a los beneficios de la seguridad social, para ellas y los niños y niñas bajo su cuidado.

\section{REFERENCIAS BIBLIOGRÁFICAS}

- Copello, Nadia Virginia. Derecho a la salud intramuros en: Revista Derecho y Salud. EUBP. Año 4. № 5. Diciembre, 2020.

- De Cicco, Andrés Oscar, Riesgo habitacional de personas vulnerables y su impacto en el derecho a la salud: la conducta omisiva del estado provincial, en Revista Derecho y Salud, 3(3).

- Grimson, Alejandro. La formación ciudadana en sociedades desiguales y heterogéneas en La educación argentina: la urgencia del largo plazo. Tedesco, Juan Carlos, compilador. Buenos Aires, Siglo veintiuno editores, 2015. P. 105.

- Moreno, Gustavo Daniel. La gran ausencia en el ejercicio de la convención. La exigibilidad de los derechos económicos, sociales y culturales en: A 30 años de la Convención sobre los derechos del niño. Avances, críticas y desafíos. Dir. Herrera, M. Gil Dominguez, A. Giosa, L. Buenos Aires, Ediar, 2019. P. 140-142.

- Ruprecht, Alfredo J. Asignaciones Familiares. Buenos Aires. 1998. Ed. Zavalía. P. 14 y 19. 